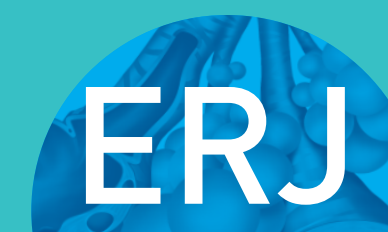

open research
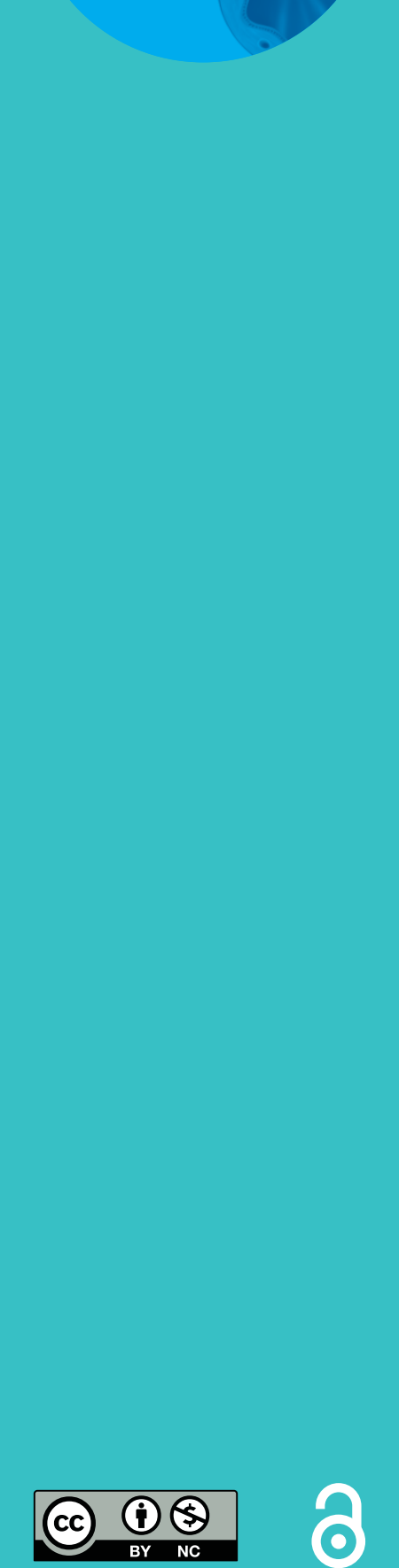

\section{Outcome of advanced lung cancer with central airway obstruction versus without central airway obstruction}

Akash Verma, Soon Keng Goh, Dessmon Y.H. Tai, Ai Ching Kor, Chun lan Soo (D, Debra G.F. Seow, Zin Nge Nge Sein, Jens Samol, Akhil Chopra (D) and John Abisheganaden

Affiliation: Dept of Respiratory and Critical Care Medicine, Tan Tock Seng Hospital, Singapore.

Correspondence: Akash Verma, Tan Tock Seng Hospital, Dept of Respiratory and Critical Care Medicine, 11 Jalan Tan Tock Seng, 308433, Singapore. E-mail: Akash_VermaQttsh.com.sg

ABSTRACT Patients with central airway obstruction (CAO) from advanced lung cancer present with significant morbidity and are assumed to have lower survival. Hence, they are offered only palliative support. We asked if patients who have advanced lung cancer with CAO (recanalised and treated) will behave similarly to those with advanced lung cancer without CAO.

This study was a retrospective review of the medical records of the patients managed for advanced lung cancer during 2010 and 2015 at our institution.

85 patients were studied. Median survival and 1-, 2- and 5-year survival were 5.8 months, 30.3\%, 11.7\% and $2.3 \%$ versus 9.3 months, $35.7 \%, 9.6 \%$ and $4.7 \%$, respectively, in the $\mathrm{CAO}$ and no CAO groups $(\mathrm{p}=0.30)$. More patients presented with respiratory failure $(15(35 \%)$ versus none; $\mathrm{p}=0.0001)$ and required assisted mechanical ventilation $(10(23.3 \%)$ versus none; $\mathrm{p}=0.001)$ in the CAO group compared with the no CAO group. Fewer patients received chemotherapy in the CAO group (11 (25.5\%)) compared with the no CAO group (23 (54.7\%); p=0.008).

There was no difference in survival among patients with advanced lung cancer whether they presented with $\mathrm{CAO}$ or without $\mathrm{CAO}$. Survival was similar to those without $\mathrm{CAO}$ in patients with recanalised $\mathrm{CAO}$ despite greater morbidity and lesser use of chemotherapy, strongly advocating bronchoscopic recanalisation of CAO. These findings dispel the nihilism associated with such cases.

@ERSpublications

Survival is similar among patients with advanced lung cancer whether they present with CAO or without CAO http://ow.ly/djRE30iDH6V

Cite this article as: Verma A, Goh SK, Tai DYH, et al. Outcome of advanced lung cancer with central airway obstruction versus without central airway obstruction. ERJ Open Res 2018; 4: 001732017 [https://doi.org/10.1183/23120541.00173-2017].

Received: Jan 022018 | Accepted after revision: Feb 222018

Copyright $\odot$ ERS 2018. This article is open access and distributed under the terms of the Creative Commons Attribution Non-Commercial Licence 4.0. 


\section{Introduction}

Among all cancer related deaths, lung cancer carries the highest mortality rate globally [1]. Advanced stage (stage III and IV) at presentation is considered the factor responsible for this high mortality [2]. Extra-thoracic feature suggesting advanced stage of lung cancer is distant metastasis. Intra-thoracic features suggestive of advanced lung cancer are mediastinal infiltration with central airway obstruction (CAO), malignant pleural effusion (MPE) with or without pleural nodularity, mediastinal involvement by discreet lymph node enlargement ipsilateral or contralateral to the primary lesion, or satellite lesion in the contralateral lung [3]. Among these features, CAO is potentially the most symptomatic form of advanced lung cancer.

$30 \%$ of patients with advanced lung cancer experience CAO [4]. They often present with stridor, atelectasis, pneumonia, dyspnoea, respiratory failure requiring assisted mechanical ventilation and haemoptysis [4]. Up to $40 \%$ of lung cancer deaths may be attributable to such loco-regional disease [5]. Lung cancer associated with $\mathrm{CAO}$ is associated with a very poor prognosis. Median survival in patients having lung cancer and malignant $\mathrm{CAO}$ requiring recanalisation is 8.4 months [6]. As a result, such patients are offered only palliative support, with assumed lower survival compared with those with no $\mathrm{CAO}[7]$.

However, to our knowledge, there is only one study comparing survival in advanced lung cancer patients with recanalised $\mathrm{CAO}$ versus those with no CAO [6]. As improvement in cancer targeted therapy such as the advent of epidermal growth factor receptor-tyrosine kinase inhibitors (EGFR-TKIs) has improved survival in patients with advanced non-small cell lung cancer (NSCLC), we investigated if patients with malignant $\mathrm{CAO}$ treated with recanalisation followed by cancer targeted therapy would behave in a similar manner as patients without CAO who are treated with cancer targeted therapy alone. Hence, we conducted the current study to compare the differences in survival among patients having advanced lung cancer with CAO (recanalised and treated), and treated advanced lung cancer without CAO.

\section{Methods}

We retrospectively reviewed patients receiving treatment for advanced lung cancer between 2010 and 2015 at our centre. Variables such as demographic data, presenting symptoms, histology, stage, therapy, intervention for airway recanalisation, techniques of recanalisation, such as laser therapy and stent placement, and survival were collected. All patients with advanced (stage III and IV) lung cancer who received anti-cancer therapy in the form of combined chemo-radiotherapy or chemotherapy alone, radiotherapy alone or tyrosine kinase inhibitors (TKIs) were included.

126 patients were treated for advanced lung cancer. Based on intra-thoracic features, we divided the patient with advanced lung cancer into two subgroups: mediastinal infiltration with CAO requiring recanalisation (group A) and advanced lung cancer without CAO (group B). Patients with advanced lung cancer by virtue of malignant pleural effusion were excluded from analysis. 43 had malignant CAO requiring recanalisation (A) and 42 did not have CAO (B).

Flexible and rigid bronchoscopies were performed using standard techniques [2]. Neodymium-doped yttrium aluminium garnet (Nd-YAG) laser photoresection (Laser sonic Model 8000; Heraeus Surgical, Milpitas, CA, USA) was performed using 15-30 watts and pulse duration of $0.5-1.0 \mathrm{~s}$. In cases with extrinsic compression from malignant obstruction, ultra-flex self-expanding covered metal stents (SEMS) were deployed using standard technique. Approval was obtained from the institutional review board.

\section{Statistical analysis}

We used software (SPSS, version 17; SPSS, Chicago, IL, USA) for all statistical analyses. The results were compared using a Wilcoxon two-sample test or Fisher exact test. p-values were two sided and considered indicative of a significant difference if $<0.05$.

\section{Results}

85 patients with advanced stage lung cancer were studied. Age, sex, race, presenting features, histology, stage distribution and survival is presented in table 1.

Most patients were males (70.6\%). Cough (49.4\%) and dyspnoea (45.8\%) were the most common symptoms, and lung adenocarcinoma was the most common (35.2\%) histological subtype of lung cancer. $34(40 \%)$ and $41(48.2 \%)$ patients received chemotherapy and radiotherapy, respectively, in the whole group. Out of the 34 patients receiving chemotherapy, 11 (25.5\%) had CAO and $23(54.7 \%)$ did not $(\mathrm{p}=0.008)$. Among 41 patients receiving radiotherapy, $20(46.5 \%)$ had CAO and $21(50 \%)$ did not 


\section{TABLE 1 Characteristics of treated advanced lung cancer ( $n=85$ )}

\begin{tabular}{|c|c|}
\hline Age year & $67(48-84)$ \\
\hline Sex male & $60(70.6 \%)$ \\
\hline \multicolumn{2}{|l|}{ Race } \\
\hline Chinese & $77(90.5 \%)$ \\
\hline Malay & $6(7.0 \%)$ \\
\hline Indian & $2(2.3 \%)$ \\
\hline Advanced lung cancer with $\mathrm{CAO}$ requiring re-canalisation & $43(50.6 \%)$ \\
\hline Advanced lung cancer without $\mathrm{CAO}$ & $42(49.4 \%)$ \\
\hline \multicolumn{2}{|l|}{ Presenting symptom } \\
\hline Cough & $42(49.4 \%)$ \\
\hline Dyspnoea & $39(45.8 \%)$ \\
\hline Respiratory failure & $15(17.6 \%)$ \\
\hline Intubation for respiratory failure & $10(11.7 \%)$ \\
\hline Haemoptysis & $19(22.3 \%)$ \\
\hline Hoarseness & $3(3.5 \%)$ \\
\hline \multicolumn{2}{|l|}{ Histology } \\
\hline Adenocarcinoma & $30(35.2 \%)$ \\
\hline Squamous cell carcinoma & $19(22.3 \%)$ \\
\hline Non-small cell lung cancer & $17(20 \%)$ \\
\hline Small cell carcinoma & $10(11.7 \%)$ \\
\hline Sarcomatoid carcinoma & $3(3.5 \%)$ \\
\hline Others & $5(5.8 \%)$ \\
\hline \multicolumn{2}{|l|}{ Stage } \\
\hline Stage IIIA & $14(16.4 \%)$ \\
\hline Stage IIIB & $13(15.2 \%)$ \\
\hline Stage IV & $58(68.2 \%)$ \\
\hline Recanalisation & $43(50.6 \%)$ \\
\hline Laser resection & $25(29.4 \%)$ \\
\hline Stent placement & $17(20 \%)$ \\
\hline Both & $3(3.5 \%)$ \\
\hline \multicolumn{2}{|l|}{ Cancer specific therapy } \\
\hline Epidermal growth factor receptor mutation Exon 19 and 21 & $8(9.4 \%)$ \\
\hline Chemotherapy & $34(40 \%)$ \\
\hline Radiotherapy & $41(48.2 \%)$ \\
\hline TKI & $13(15.2 \%)$ \\
\hline \multicolumn{2}{|l|}{ Survival } \\
\hline Deaths & $72(84.7 \%)$ \\
\hline Survival months & $9.4(0.8-79.4)$ \\
\hline$<3$ months & $22(25.8 \%)$ \\
\hline$\geqslant 3$ months & $63(74.1 \%)$ \\
\hline$\geqslant 6$ months & $55(64.7 \%)$ \\
\hline$\geqslant 12$ months & $31(36.4 \%)$ \\
\hline$>24$ months & $8(9.4 \%)$ \\
\hline$\geqslant 5$ years & $4(4.7 \%)$ \\
\hline
\end{tabular}

Data are presented as median (range) unless otherwise stated. CAO: central airway obstruction; TKI: tyrosine kinase inhibitors.

( $\mathrm{p}=0.82)$. Median survival was $9.4(0.8-79.4)$ months in the whole group. 1-year, 2-year and 5-year survival was $36.4 \%, 9.4 \%$ and $4.7 \%$, respectively.

\section{Subgroup analysis of $C A O$ versus no $C A O$ (group $A$ versus group $B$ )}

In the subgroup analysis of group A and group B, there was no difference in demographic features, stage of cancer or survival table 2. However, more patients in group A presented with dyspnoea, respiratory failure and haemoptysis due to CAO ( $\mathrm{p}=0.0001)$. Squamous cell carcinoma was the common histological sub-type in this group $(\mathrm{p}=0.001)$ and fewer patients received chemotherapy $(\mathrm{p}=0.008)$. Median survival was statistically insignificant, $5.8(0.32-62)$ months versus $9.3(0.8-78.3)$ months, $p=0.30$ in patients with $\mathrm{CAO}$ and without $\mathrm{CAO}$ respectively figure 1 . 1-year, 2 -year and 5 -year survival rate were $30.3 \%, 11.7 \%$ and $2.3 \%$, respectively, in the CAO group versus $35.7 \%, 9.6 \%$ and $4.7 \%$, respectively, in patients without CAO without any significant difference among the two groups (table 2). 
TABLE 2 Subgroup analysis of advanced lung cancer with CAO ( $n=43)$ or without CAO (n=42): demographic features, presenting features, histology, stage, therapy and outcomes

\begin{tabular}{|c|c|c|c|}
\hline & \multicolumn{3}{|c|}{ Treated advanced lung cancer } \\
\hline & $\begin{array}{l}\text { With } \mathrm{CAO} \text { requiring } \\
\text { re-canalisation }\end{array}$ & Without CAO & p-value \\
\hline Age years & $63(32-86)$ & $67(48-84)$ & 0.49 \\
\hline Sex male & $32(74.4 \%)$ & $30(71.4 \%)$ & 0.81 \\
\hline \multicolumn{4}{|l|}{ Pleural effusion } \\
\hline Central airway obstruction & $43(100 \%)$ & & 0.0001 \\
\hline \multicolumn{4}{|l|}{ Presenting symptom } \\
\hline Cough & $17(39.5 \%)$ & $25(59.6 \%)$ & 0.08 \\
\hline Dyspnoea & $25(58.1 \%)$ & $14(33.3 \%)$ & 0.02 \\
\hline Respiratory failure & $15(35 \%)$ & & 0.0001 \\
\hline Intubation for respiratory failure & $10(23.3 \%)$ & & 0.001 \\
\hline Haemoptysis & $6(14 \%)$ & $13(31 \%)$ & 0.07 \\
\hline Hoarseness & 0 & $3(7.1 \%)$ & 0.11 \\
\hline \multicolumn{4}{|l|}{ Histology } \\
\hline Adenocarcinoma & $13(30.2 \%)$ & $17(40.4 \%)$ & 0.36 \\
\hline Squamous cell carcinoma & $16(37.2 \%)$ & $3(7.1 \%)$ & 0.001 \\
\hline Non-small cell lung cancer & $8(18.6 \%)$ & $9(21.4 \%)$ & 0.79 \\
\hline Small cell carcinoma & $3(6.9 \%)$ & $7(16.6 \%)$ & 0.18 \\
\hline Sarcomatoid carcinoma & $2(4.6 \%)$ & $1(2.3 \%)$ & 1.0 \\
\hline Others & $1(2.3 \%)$ & $4(9.5 \%)$ & 0.20 \\
\hline \multicolumn{4}{|l|}{ Stage } \\
\hline Stage IIIA & $10(23.3 \%)$ & $4(9.6 \%)$ & 0.14 \\
\hline Stage IIIB & $8(18.7 \%)$ & $5(12 \%)$ & 0.54 \\
\hline Stage IV & $25(58.2 \%)$ & $33(78.6 \%)$ & 0.06 \\
\hline \multicolumn{4}{|l|}{ Cancer specific therapy } \\
\hline $\begin{array}{l}\text { Epidermal growth factor receptor } \\
\text { mutation exon } 19 \text { and } 21\end{array}$ & $4(9.3 \%)$ & $4(9.5 \%)$ & 1.0 \\
\hline Chemotherapy & $11(25.5 \%)$ & $23(54.7 \%)$ & 0.008 \\
\hline Radiotherapy & $20(46.5 \%)$ & $21(50 \%)$ & 0.82 \\
\hline TKI & $4(9.3 \%)$ & $9(21.4 \%)$ & 0.14 \\
\hline \multicolumn{4}{|l|}{ Survival } \\
\hline Deaths & $32(74.4 \%)$ & 40 (95.2\%) & 0.26 \\
\hline Survival months & $5.8(0.32-62)$ & $9.3(0.8-78.3 \%)$ & 0.30 \\
\hline$<3$ months & $13(30.3 \%)$ & $11(26.2 \%)$ & 1.0 \\
\hline$\geqslant 3$ months & $30(69.8 \%)$ & $31(73.9 \%)$ & 0.81 \\
\hline$\geqslant 6$ months & $20(46.6 \%)$ & $27(64.3 \%)$ & 0.12 \\
\hline$\geqslant 12$ months & $13(30.3 \%)$ & $15(35.7 \%)$ & 0.64 \\
\hline$>24$ months & $5(11.7 \%)$ & $4(9.6 \%)$ & 1.0 \\
\hline$\geqslant 5$ year & $1(2.3 \%)$ & $2(4.7 \%)$ & 0.61 \\
\hline
\end{tabular}

Data are presented as median (range) unless otherwise stated. CAO: central airway obstruction; TKI: tyrosine kinase inhibitor.

\section{Discussion}

We demonstrated that there was no difference in survival among patients with treated advanced lung cancer whether they presented with CAO or without CAO. This similar survival was seen despite greater morbidity and lesser use of chemotherapy in patients with re-canalized CAO group, strongly advocating bronchoscopic re-canalisation of CAO.

\section{Survival with and without CAO}

Median survival and 1-year survival rate were similar in patients with recanalised CAO and without CAO. While median survival in "untreated" advanced lung cancer is reported as 4 to 5 months with survival rate at 1 year of $10 \%$, the median survival in patients receiving platinum-based chemotherapy for advanced lung cancer is reported as 8 to 12 months with survival rate at 1 year of $33 \%[8,9]$. In this context, survival rate in our cohort regardless of presence or absence of CAO was similar to the overall survival reported with platinum-based chemotherapy.

These findings are consistent with existing literature. The median survival and 1-year survival rate in our cohort of malignant $\mathrm{CAO}$ treated with recanalisation by bronchoscopic laser resection or stenting was 


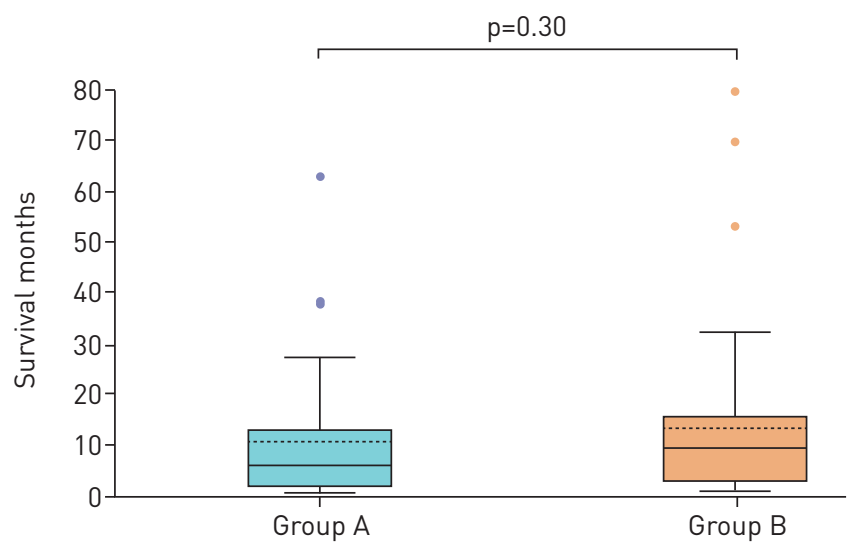

FIGURE 1 Box plot showing the comparison of survival in the sub-groups. The first box plot is showing group A (recanalised central airway obstruction) with median survival of 5.8 months in comparison to the second box plot showing group B (no central airway obstruction) with median survival of 9.3 months; $p=0.30$.

5.8 months and $30.3 \%$, similar to 6.2 months and $25 \%$ reported by SAJI et al. [10] in Japanese population, and 8.4 months and $40 \%$ reported by CHHAJED et al. [6] in malignant CAO in the European population. CHHAJED et al. [6] also reported similar survival between patients having advanced lung cancer with locally treated malignant $\mathrm{CAO}$ and those without CAO. In another study by Ross et al. [11], improvement in survival and level of function was described following Nd-YAG laser photoresection of the exophytic tumour obstructing central airways.

A greater proportion of patients in the CAO group in our cohort presented with dyspnoea, respiratory failure (requiring assisted mechanical ventilation) and haemoptysis. However, despite this, the survival was unaffected. This lack of detrimental effect of this greater morbidity at initial presentation on survival in this group invalidates the perception that these patients have poorer survival than those without CAO. The effect of bronchoscopic recanalisation on survival can be explained by the prompt reversal of the respiratory failure averting premature death and restoration of more stable clinical condition to allow opportunity for administration of subsequent therapies [10, 12-16].

Squamous cell carcinoma was the most common histology in patients with CAO in our cohort than patients without $\mathrm{CAO}$ in whom adenocarcinoma was more common. This is consistent with literature as squamous cell carcinoma involves the central airways preferentially and accounts for more than half of the NSCLC involving the airways [17, 18].

Fewer patients received chemotherapy in the CAO group. The reason for this is unclear. However, it is noteworthy that despite fewer patients receiving chemotherapy in the CAO group, the survival remained unaffected and similar to patients without CAO.

These findings of equivalent survival in patients with $\mathrm{CAO}$ compared to without CAO despite greater proportion presenting with life threatening symptoms, and fewer receiving chemotherapy speaks strongly in favour of aggressive management of patients with $\mathrm{CAO}$ with the provision of assisted mechanical ventilation if needed, timely re-canalisation using bronchoscopic techniques, followed by radiation therapy and/or chemotherapy.

It is known that platinum-based chemotherapy confers partial responses in approximately $30 \%$ of patients with advanced NSCLC $[19,20]$. However, treatment with EGFR-TKIs is associated with higher response rates and survival in patients whose cancer demonstrates activating EGFR mutations [21-24]. Adenocarcinoma is the most common histological sub-type of lung cancer. Activating EGFR mutation targetable by the TKIs is also only observed in adenocarcinoma sub-type. Consequently, greater proportions of patients with adenocarcinoma are eligible for TKI therapy which, in turn, is associated with improved survival [24]. Furthermore, the advent of immunotherapy carries even greater promise for better outcomes. This speaks against taking conservative approach for these patients.

In conclusion, there was no difference in survival among patients with advanced lung cancer whether they presented with $\mathrm{CAO}$ or without CAO. Similar survival was seen in patients with recanalised CAO or without CAO despite greater morbidity and lesser use of chemotherapy in the former group, strongly advocating bronchoscopic recanalisation of CAO. These findings dispel the nihilism associated with such cases. 
Acknowledgements: The authors would like to thank Ivy Yu Ling Ling (Dept of Respiratory and Critical Care Medicine, Tan Tock Seng Hospital, Singapore) for her valuable contribution in editing the figure and administrative work.

Conflict of interest: None declared.

\section{References}

1 GLOBOCAN 2008. International Agency for Research on Cancer. Cancer Incidence, Mortality and Prevalence Worldwide in 2008. Available from http://globocan.iarc.fr/factsheets/cancers/lung.asp. Date last accessed: November 12, 2017.

2 Pearson FG. Current status of surgical resection for lung cancer. Chest 1994; 106: 337S.

3 Silvestri GA, Gonzalez AV, Jantz MA, et al. Methods for staging non-small cell lung cancer: Diagnosis and management of lung cancer, 3rd Ed: American College of Chest Physicians evidence-based clinical practice guidelines. Chest 2013; 143: 5 Suppl., e211S-e250S.

4 Ginsberg RJ, Vokes EE, Ruben A. Non-small cell lung cancer. In: DeVita VT, Hellman S, Rosenberg SA, eds. Cancer: principles and practice of oncology. 5th Edn. Philadelphia, Lippincott-Raven, 1997; pp. 858-911.

5 Noppen M, Meysman M, D'Haese J, et al. Interventional bronchoscopy: 5-year experience at the Academic Hospital of the Vrije Universiteit Brussel (AZ-VUB). Acta Clin Belg 1997; 52: 371-380.

6 Chhajed PN, Baty F, Pless M, et al. Outcome of treated advanced non-small cell lung cancer with and without central airway obstruction. Chest 2006; 130: 1803-1807.

7 Vonk-Noordegraaf A, Postmus PE, Sutedja TG. Tracheo-bronchial stenting in the terminal care of cancer patients with central airways obstruction. Chest 2001; 120: 1811-1814.

8 Michael Alberts W. Pulmonary Board Review. Lenexa, American College of Chest Physicians, 2009.

9 Seijo LM, Sterman DH. Interventional pulmonology. N Engl J Med 2001; 344: 740-749.

10 Saji H, Furukawab K, Tsutsuia H, et al. Outcomes of airway stenting for advanced lung cancer with central airway obstruction. Interactive Cardiovasc Thorac Surg 2010; 11: 425-428.

11 Ross D, Mohsenifar Z, Koerner SK. Survival characteristics after neodymium: YAG laser photoresection in advanced stage lung cancer. Chest 1990; 98: 583.

12 Hespanhol V, Magalhães A, Marques A. Neoplastic severe central airways obstruction, interventional bronchoscopy: a decision-making analysis. J Thorac Cardiovasc Surg 2013; 145: 926-932.

13 Perrin G, Colt HG, Martin C, et al. Safety of interventional rigid bronchoscopy using intravenous anaesthesia and spontaneous assisted ventilation: a prospective study. Chest 1992; 102: 1526-1530.

14 Lo CP, Hsu AA, Eng P. Endobronchial stenting in patients requiring mechanical ventilation for major airway obstruction. Ann Acad Med Singapore 2000; 29: 66-70.

15 Murgu S, Langer S, Colt H. Bronchoscopic intervention obviates the need for continued mechanical ventilation in patients with airway obstruction and respiratory failure from inoperable non-small-cell lung cancer. Respiration 2012; 84: 55-61.

16 Colt HG, Harrell JH. Therapeutic rigid bronchoscopy allows level of care changes in patients with acute respiratory failure from central airways obstruction. Chest 1997; 112: 202-206.

17 Cosano PA, Muñoz CL, Cosano Povedano FJ, et al. Endoscopic treatment of central airway stenosis: five years' experience. Arch Bronconeumol 2005; 41: 322-327.

18 Chhajed PN, Eberhardt R, Dienemann $\mathrm{H}$, et al. Therapeutic bronchoscopy interventions before surgical resection of lung cancer. Ann Thorac Surg 2006; 81: 1839-1843.

19 D'Addario G, Pintilie M, Leighl NB, et al. Platinum-based versus non-platinum-based chemotherapy in advanced non-small-cell lung cancer: a meta-analysis of the published literature. J Clin Oncol 2005; 23: 2926-2936.

20 Wu S-G, Yu C-J, Tsai M-F, et al. Survival of lung adenocarcinoma patients with malignant pleural effusion. Eur Respir J 2013; 41: 1409-1418.

21 Brugger W, Triller N, Blasinska-Morawiec M, et al. Prospective molecular marker analyses of EGFR and KRAS from a randomized, placebo-controlled study of erlotinib maintenance therapy in advanced non-small-cell lung cancer. J Clin Oncol 2011; 29: 4113-4120.

22 Zhu CQ, da Cunha Santos G, Ding K, et al. National Cancer Institute of Canada Clinical Trials Group Study BR.21 Role of KRAS and EGFR as biomarkers of response to erlotinib in National Cancer Institute of Canada Clinical Trials Group Study BR.21. J Clin Oncol 2008; 26: 4268-4275.

23 Douillard JY, Shepherd FA, Hirsh V, et al. Molecular predictors of outcome with gefitinib and docetaxel in previously treated non-small-cell lung cancer: data from the randomized phase III INTEREST trial. J Clin Oncol 2010; 28: 744-752.

24 Shigematsu H, Lin L, Takahashi T, et al. Clinical and biological features associated with epidermal growth factor receptor gene mutations in lung cancers. J Natl Cancer Inst 2005; 97: 339-346. 